\title{
Liver Transaminase Levels and Neutrophil to Lymphocyte Ratio as Prognostic and Predictor in Coronavirus Disease 2019
}

\author{
Jonathan Arifputra ${ }^{1 *}$, Bradley Jimmy Waleleng ${ }^{2}$, Fandy Gosal ${ }^{2}$, Nelly Tendean Wenas ${ }^{2}$, Luciana Rotty ${ }^{2}$, Jeanne Winarta ${ }^{2}$, \\ Andrew Waleleng ${ }^{2}$ \\ ${ }^{1}$ Department of Internal Medicine, Faculty of Medicine, Sam Ratulangi University, Prof. Dr. R. D. Kandou Hospital, Manado, \\ Indonesia; ' Division of Gastroenterology-Hepatology, Department of Internal Medicine, Faculty of Medicine, Sam Ratulangi \\ University, Prof. Dr. R. D. Kandou Hospital, Manado, Indonesia
}

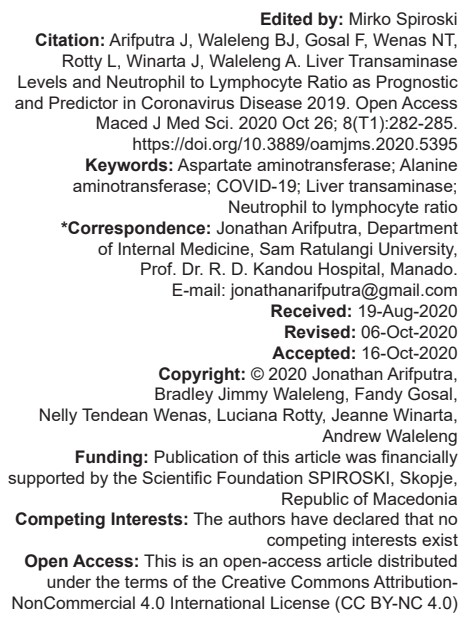

\section{Abstract}

BACKGROUND: Coronavirus disease 2019 (COVID-19) was a disease caused by the severe acute respiratory syndrome coronavirus-2 (SARS-CoV-2) virus with severe respiratory distress syndrome. SARS-CoV-2 can attack the gastrointestinal and liver system. In several studies, elevated levels of alanine aminotransferase (ALT) and aspartate aminotransferase (AST) were reported, ranging from $14 \%$ to $53 \%$. The increase of neutrophil to lymphocyte ratio (NLR) also increases the risk of mortality in COVID-19.

AIM: This research wants to study ALT, AST, and NLR as prognostic and predictor in COVID-19.

METHODS: A cross-sectional retrospective study was conducted on COVID-19 patients. The diagnostic criteria are based on the recommendations of the Indonesian Ministry of Health. The patient's blood was examined in a central laboratory at the hospital. Data analysis was done using SPSS version 22.

RESULTS: A total of 126 patients with COVID-19 were included in this study. There are $57(45.2 \%)$ patients having abnormal liver test. There was a significant difference in the mean AST and NLR between non-survival and survival outcome in COVID-19 patients (82.91 \pm 103.82 vs. $40.54 \pm 33.59 \mathrm{U} / \mathrm{L} ; \mathrm{p}=0.0001$ and $7.42 \pm 3.65$ vs. $3.47 \pm 2.41$ $p=0.0001)$. High AST ( $\geq 34.5 \mathrm{U} / \mathrm{L})$ and NLR $(\geq 4.7)$ independently associated with non-survival outcome in COVID-19 patient with odds ratio 5.31 and $9.49(1.89-14.95,95 \%$ confidence interval $[\mathrm{Cl}] ; p=0.002$ and $3.57-25.22,95 \% \mathrm{Cl}$; $\mathrm{p}=0.0001)$.

CONCLUSION: This study revealed that high AST and NLR at hospital admission were associated with high mortality risk in COVID-19 patients. Therefore, AST and NLR can be a significant prognostic of outcome in COVID-19 patients.

\section{Introduction}

At the end of 2019, it was discovered pneumonia caused by the severe acute respiratory syndrome coronavirus-2 (SARS-CoV-2) virus in Wuhan, China, which was named coronavirus disease 2019 (COVID-19). COVID-19 was declared a pandemic in the world by the World Health Organization (WHO) at the end of March 2020. SARSCoV-2 has an almost identical genome sequence with SARS-CoV. SARS-CoV-2 can be transmitted between humans through close contact and air droplets inhalation. So far, COVID-19 has spread in 215 countries around the world [1], [2].

Viral pneumonia is the primary manifestation of COVID-19, which has symptoms such as fever, fatigue, dry cough, anosmia, and headache. Lately, several studies show that COVID-19 can also attack other organs besides the respiratory system, such as the gastrointestinal and liver system. This is due to the spread of main viral entry, angiotensin-converting enzyme 2 (ACE2), which is abundant in other organs such as the upper esophagus, enterocytes of the ileum and colon, liver, and bile duct cells [3], [4]

The neutrophil to lymphocyte ratio (NLR) is an easy test to do, by dividing the absolute count of neutrophils by the absolute count of lymphocytes. NLR was reported to indicate the inflammatory status of patients. Increased NLR was a factor in the risk of mortality from various diseases such as cancer, acute coronary syndrome, and cerebral hemorrhage. Recent research has also revealed that increasing the NLR value also increases the risk of mortality in COVID-19 [5], [6], [7].

Liver impairment has also been reported as a common manifestation, although it is not a prominent feature of the illness. Several studies have shown different degrees of elevated serum liver biochemistries in COVID-19 patients, mainly indicated by abnormal alanine aminotransferase (ALT) and aspartate aminotransferase (AST) levels. Recent studies have found that SARS-CoV-2 can bind to ACE2 in cholangiocytes, which triggers cholangiocyte dysfunction and triggers a systemic inflammatory 
response that ends with liver injury. In several studies, elevated levels of ALT and AST were reported, ranging from $14 \%$ to $53 \%$ [8], [9]. It remains unclear whether these laboratory test alterations are associated with a worse prognosis. This research wants to study ALT, AST, and NLR's comparison of patient outcome and their best cut point for outcome prediction in COVID-19 patients.

\section{Methods}

\section{Patient selection}

This study was a cross-sectional retrospective study conducted on COVID-19 patients who had been confirmed at Prof. Dr. R.D. Kandou hospital. Inclusion criteria are stated as follows: Male or female aged $\geq 18$ years old, patients were diagnosed with COVID-19. From March 1, to June 30, 2020, 145 patients were diagnosed with COVID-19 based on the guideline for diagnosis and prevention coronavirus 2019 in Indonesia. This study was approved by the Local Ethics Committee.

\section{Confirmation of COVID-19}

The presence of SARS-CoV-2 was detected by real-time reverse transcription PCR. Two pairs of primers targeting the open reading frame $1 \mathrm{ab}$ (ORF1ab) and the nucleocapsid protein $(\mathrm{N})$ were amplified and examined. The corresponding sequences for ORF1ab were 5'-CCCTGTGGGTTTTACACTTAA-3' $(\mathrm{F}), \quad$ 5'-ACGATTGTGCATCAGCTGA-3' (R), and 5'-CY3-CCGTCTGCGGTATGTGGAAAGGTTATGGBHQ1-3' (probe), and those for $\mathrm{N}$ were 5 ' - G G G GA A C T T C T C C T G C TA GAAT - 3 ' ( F ), 5'-CAGACATTTTGCTCTCAAGCTG-3'(R), and 5'-FAM-TTGCTGCTGCTTGACAGATT-TAMRA3'(probe). These diagnostic criteria are based on the recommendations of the Indonesian Ministry of Health.

\section{Data collection}

Medical records from 145 patients were collected and examined by researchers. Identity, laboratory, and outcome data from patients were obtained from the hospital information system. Patient outcomes are categorized as survival and non-survival.

\section{$N L R, A L T$, and AST}

The patient serum and peripheral venous blood were taken from all COVID-19 patients who were confirmed when the patient entered the hospital. The patient's blood was examined in the central laboratory at Prof Dr. R.D. Kandou Hospital following the hospital's standard operative procedures. Liver test abnormalities were defined as the elevation of AST $>40 \mathrm{U} / \mathrm{L}$ and ALT $>40 \mathrm{U} / \mathrm{L}[9]$.

\section{Statistical analysis}

Data analysis was performed through univariate and bivariate analyses using the SPSS $22^{\text {nd }}$ version (SPSS Inc., Chicago) with a 95\% confidence interval $(\mathrm{Cl})$. Bivariate analysis was performed using Mann-Whitney. Multivariate analysis was performed using logistic regression. Data were also analyzed using receiver operating characteristic (ROC) curve and Youden's index, $p<0.05$ was considered statistically significant.

\section{Results}

In this study, 145 confirmed COVID-19 patients were found, but only 126 patients had complete data. Of the total, 126 patients consisted of 60 men (47.6\%) and 66 women (52.4\%). A total of $32(25.4 \%)$ patients died during hospitalization. The mean age of the patients was $48.81 \pm 15.70$ years. There are $57(45.2 \%)$ patients with an abnormal liver test consisted of increasing AST (38.1\%) and ALT (31\%). The baseline characteristics of the patients are shown in Table 1. NLR, AST, and ALT were higher in non-survival than survival outcomes in COVID-19 patients (Table 1).

There was a significant difference in the mean AST levels between non-survival and survival outcomes in COVID-19 patients. Patients in the non-survival group had higher AST levels than the survival group (82.91 \pm 103.82 vs. $40.54 \pm 33.59 \mathrm{U} / \mathrm{L} ; \mathrm{p}=0.0001$ ) (Table 1).

There was no significant difference in the mean ALT levels between non-survival and survival outcomes in COVID-19 patients (56.72 \pm 71.71 vs. $34.57 \pm 32.28$ $\mathrm{U} / \mathrm{L} ; \mathrm{p}=0.136)$ (Table 1).

There was a significant difference in the mean NLR between non-survival and survival outcomes

Table 1: Basic characteristics of the study population

\begin{tabular}{|c|c|c|c|c|c|c|c|c|c|c|c|c|c|}
\hline \multirow[t]{3}{*}{ Characteristics } & \multicolumn{12}{|c|}{ Outcome } & \multirow[t]{3}{*}{$\mathrm{p}$} \\
\hline & \multicolumn{6}{|c|}{ Non-survival } & \multicolumn{6}{|c|}{ Survival } & \\
\hline & $\mathrm{n}$ & Min & Max & Median & Mean & SD & $\mathrm{n}$ & Min & Max & Median & Mean & SD & \\
\hline Age (years) & 32 & 32.00 & 80.00 & 58.50 & 57.31 & 12.14 & 94 & 19.00 & 82.00 & 44.00 & 45.91 & 15.78 & 0.0001 \\
\hline NLR & 32 & 1.71 & 15.17 & 7.04 & 7.42 & 3.65 & 94 & 0.70 & 13.00 & 2.58 & 3.47 & 2.41 & 0.0001 \\
\hline AST (U/L) & 32 & 21.00 & 544.00 & 50.00 & 82.91 & 103.82 & 94 & 15.00 & 207.00 & 30.00 & 40.54 & 33.59 & 0.0001 \\
\hline ALT (U/L) & 32 & 10.00 & 358.00 & 30.00 & 56.72 & 71.71 & 94 & 3.00 & 198.00 & 25.00 & 34.57 & 32.28 & 0.136 \\
\hline
\end{tabular}


in COVID-19 patients. Patients in the non-survival had NLR significantly higher than the survival group $(7.42 \pm 3.65$ vs. $3.47 \pm 2.41 ; p=0.0001)$ (Table 1)

Analysis using the ROC test showed that AST had an area under the ROC of $0.739(p=0.0001)$, and NLR had an area under the ROC of $0.830(p=0.0001)$ (Figure 1).

Youden's index was calculated to determine the best AST and NLR cut off point to give better sensitivity dan specificity to predict COVID-19 patients' outcome. For AST, the best cutoff point was $34.5 \mathrm{U} / \mathrm{L}$ to get $78.12 \%$ sensitivity and $61.70 \%$ specificity, and for NLR, the best cutoff point was 4.7 to get $75 \%$ sensitivity and $79.78 \%$ specificity.

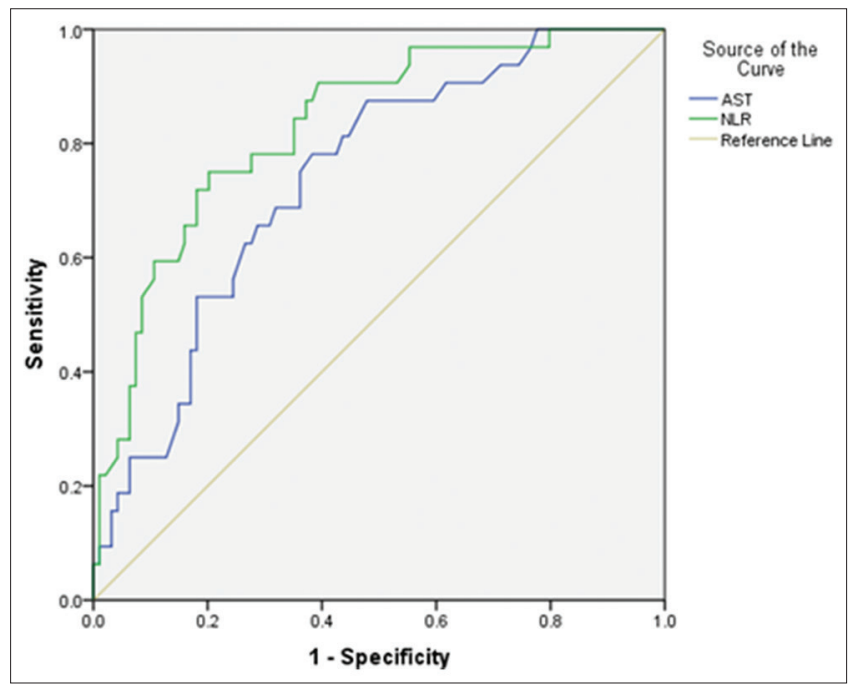

Figure 1: ROC curve of AST and NLR

After logistic regression analysis was performed, high AST ( $\geq 34.5 \mathrm{U} / \mathrm{L})$ and NLR $(\geq 4.7)$ remained independently associated with non-survival outcome in COVID-19 patient with odds ratio 5.31 (1.89-14.95, 95\% Cl; $\mathrm{p}=0.002)$ and 9.49 (3.57-25.22, $95 \% \mathrm{Cl} ; \mathrm{p}=0.0001$ ), respectively (Table 2 ).

Table 2. Logistic regression analysis of predictors of COVID-19 patients' mortality

\begin{tabular}{lll}
\hline Variable $^{a}$ & OR $(95 \% \mathrm{Cl})$ & $\mathrm{p}$ \\
\hline AST $(\geq 34.5 \mathrm{U} / \mathrm{L})$ & $5.31(1.89-14.95)$ & 0.002 \\
NLR $(\geq 4.7)$ & $9.45(3.57-25.22)$ & 0.0001 \\
\hline Cl: Confidence interval; OR: Odds ratio; 'adjusted for gender. NLR: Neutrophil to lymphocyte ratio, AST:
\end{tabular}
Aspartate aminotransferase

\section{Discussion}

In this study, $45.2 \%$ of COVID-19 patients had abnormal liver tests, where there was an increase in AST by $38.1 \%$ and ALT by $31 \%$. Fan et al. also found that there were abnormal liver tests in $37.1 \%$ of patients with COVID-19 [10]. This result is almost the same as the study conducted by Chen et al., where the increase in AST was $35 \%$, and ALT was $28 \%$ [11].
Liver impairment is closely related to mortality in COVID-19 patients. In this study, it was found that AST and ALT values were higher in COVID-19 patients with the non-survival group, where statistically, AST levels had a significant difference between COVID-19 patients with non-survival and survival outcome $(p<0.05)$. Several studies also found that AST increases more frequently than ALT in severe COVID-19 patients [12], [13]. A study conducted by Lei et al. gave similar results, in which patients with elevated AST had a high risk of mortality [14].

Several studies have shown that SARS-CoV-2 requires ACE2 as a receptor to enter cells, where ACE2 is mainly expressed in the heart, lungs, and kidneys. In addition, ACE2 is also slightly expressed in the colon and liver. The previous studies have shown that ACE2 expression is present in cholangiocytes, suggesting that cholangiocyte is the direct target of SARS-CoV-2 to attack the liver. The increase in AST and ALT is an indicator of liver cell damage. However, pathological analysis of the liver tissue of COVID-19 patients failed to prove that cholangiocyte damage and viral infiltration in liver tissue occurred. The specific cause of liver damage and elevated liver transaminase enzymes is not clear and needs further study [8], [9], [14], [15], [16], [17], [18], [19].

In this study, it was found that there was an increase in NLR in COVID-19 patients with the nonsurvival outcome, which was statistically significant when compared with COVID-19 patients with survival outcome $(p<0.05)$. Liu et al. also obtained the same results, where a higher increase in NLR was associated with an increased risk of mortality in COVID-19 patients [7] Research conducted by Yan et al. also found the same thing [20].

NLR is an easy method to evaluate the systemic inflammatory response, where the NLR is calculated by taking the neutrophil and lymphocyte values into account. Neutrophils play an important role in the innate immune response, while lymphocytes play an important role in the inflammatory response. The increase in NLR results from an inflammatory response that stimulates neutrophil production and accelerates the apoptosis of inflammatory lymphocytes. Increased neutrophils result in increased systemic arginase activity, which depletes systemic arginase reserves. Where arginine is a single subtract for the formation of nitric oxide (NO), which has antiviral activity against RNA viruses such as SARSCoV-2. Therefore, an increase in NLR indicates an imbalance of the inflammatory response that can result in death [7], [20], [21].

Based on the ROC curve analysis, the AST and NLR showed the significant performance to predict COVID-19 patient's mortality. The best cut-off point for AST and NLR was $34.5 \mathrm{U} / \mathrm{L}$ and 4.7. This study supports that a high AST ( $\geq 34.5 \mathrm{U} / \mathrm{L})$ and NLR $(\geq 4.7)$ are a strong predictor for mortality in patients with COVID-19. COVID-19 patients with high AST and NLR were 5.31 and 9.49 times more likely to have a nonsurvival outcome. However, a scoring system is needed 
to assess the prognosis of COVID-19. It is hoped that the prognosis will be more accurate with scoring system so that early treatment can be given.

There are some limitations to this study. First, this study was retrospective, and there some cases did not have enough data. Second, we did not do multiple testing of liver transaminase enzymes and NLR during hospitalization. Third, all subjects in this study were Manado patients with COVID-19, so this study's results might not directly be applied to other races.

\section{Conclusion}

This study revealed that high AST and NLR at hospital admission were associated with high mortality risk in COVID-19 patients. Therefore, AST and NLR can be a significant prognostic of outcome in COVID-19 patients. However, a scoring system is needed to have a more accurate prediction of prognosis.

\section{References}

1. Zhu N, Zhang D, Wang W, Li X, Yang B, Song J, et al. A nove coronavirus from patients with pneumonia in China, 2019. N Engl J Med. 2020;382(8):727-33.

PMid:31978945

2. World Health Organization. Coronavirus Disease 2019 (COVID-19) Situation Report-201; 2020. Available from: https://www.who.int/docs/default-source/coronaviruse/ situation-reports/20200808-covid-19-sitrep-201. pdf?sfvrsn=121bb855_2. [Last accessed on 2020 Aug 08].

3. Jin $\mathrm{Y}$, Yang $\mathrm{H}$, Ji W, Wu W, Chen $\mathrm{S}$, Zhang $\mathrm{W}$, et al. Virology, epidemiology, pathogenesis, and control of covid-19. Viruses. 2020;12(4):1-17.

PMid:32230900

4. Adiwinata R, Irawan VR, Arifputra J, Waleleng BJ, Gosal F, Rotty L, et al. Potential of fecal-oral transmission and gastrointestinal manifestation of COVID-19. Indones J Gastroenterol Hepatol Dig Endosc. 2020;21(1):53. https://doi. org/10.24871/211202053-58

5. Faria SS, Fernandes PC, Silva MJ, Lima VC, Fontes W, Freitas-Junior $\mathrm{R}$, et al. The neutrophil-to-lymphocyte ratio: $A$ narrative review. Ecancermedicalscience. 2016;10:1-12. https:// doi.org/10.3332/ecancer.2016.702

PMid:28105073

6. Forget P, Khalifa C, Defour JP, Latinne D, Van Pel MC, De Kock $M$. What is the normal value of the neutrophil-tolymphocyte ratio? BMC Res Notes. 2017;10(1):1-4. https://doi. org/10.1186/s13104-016-2335-5

PMid:28057051

7. Liu Y, Du X, Chen J, Jin Y, Peng L, Wang HH, et al. Neutrophilto-lymphocyte ratio as an independent risk factor for mortality in hospitalized patients with COVID-19. J Infect. 2020;81(1):e6-12. https://doi.org/10.1016/j.jinf.2020.04.002

PMid:32283162

8. Garrido I, Liberal R, Macedo G. Review article: COVID-19 and liver disease-what we know on 1st May 2020. Aliment Pharmacol Ther. 2020;52(2):267-75. https://doi.org/10.1111/apt.15813 PMid:32402090

9. Cai Q, Huang D, Yu H, Zhu Z, Xia Z, Su Y, et al. COVID-19: Abnormal liver function tests. J Hepatol. 2020;73(3):566-74. PMid:32298767

10. Fan Z, Chen L, Li J, Cheng X, Yang J, Tian C, et al. Clinical features of COVID-19-related liver functional abnormality. Clin Gastroenterol Hepatol. 2020;18(7):1561-6.

11. Chen N, Zhou M, Dong $X, Q u ~ J$, Gong $F$, Han $Y$, et al. Epidemiological and clinical characteristics of 99 cases of 2019 novel coronavirus pneumonia in Wuhan, China: A descriptive study. Lancet. 2020;395(10223):507-13. https://doi.org/10.1016/ s0140-6736(20)30211-7

PMid:32007143

12. Guan WJ, Ni ZY, Hu Y, Liang WH, Ou CQ, He JX, et al. Clinical characteristics of coronavirus disease 2019 in China. N Engl J Med. 2020;382(18):1708-20.

13. Wang D, Hu B, Hu C, Zhu F, Liu X, Zhang J, et al. Clinical characteristics of 138 hospitalized patients with 2019 novel coronavirus-infected pneumonia in Wuhan, China. JAMA. 2020;323(11):1061-9. https://doi.org/10.1001/jama.2020.1585 PMid:32031570

14. Lei F, Liu YM, Zhou F, Qin JJ, Zhang P, Zhu L, et al. Longitudinal association between markers of liver injury and mortality in COVID-19 in China. Hepatology. 2020;72:389-98. PMid:32359177

15. Feng G, Zheng KI, Yan QQ, Rios RS, Targher G, Byrne CD, et al COVID-19 and liver dysfunction: Current insights and emergent therapeutic strategies. J Clin Transl Hepatol. 2020;8(1):18-24. https://doi.org/10.14218/jcth.2020.00018 PMid:32274342

16. Youssef $M$, Hussein $M$, Attia AS, Elshazli RM, Omar $M$, Zora G, et al. COVID-19 and liver dysfunction: A systematic review and meta-analysis of retrospective studies. J Med Virol. 2020;92(10):1825-33. https://doi.org/10.1002/jmv.26055 PMid:32445489

17. Zhang $\mathrm{Y}$, Zheng L, Liu L, Zhao M, Xiao J, Zhao Q. Liver impairment in COVID-19 patients: A retrospective analysis of 115 cases from a single centre in Wuhan city, China. Liver Int. 2020;40(9):2095-103. https://doi.org/10.1111/liv.14455 PMid:32239796

18. Xu L, Liu J, Lu M, Yang D, Zheng X. Liver injury during highly pathogenic human coronavirus infections. Liver Int. 2020;40(5):998-1004. https://doi.org/10.1111/liv.14435 PMid:32170806

19. Alqahtani SA, Schattenberg JM. Liver injury in COVID-19: The current evidence. United Eur Gastroenterol J. 2020;8(5):509-19. PMid:32450787

20. Yan X, Li F, Wang X, Yan J, Zhu F, Tang S, et al. Neutrophil to lymphocyte ratio as prognostic and predictive factor in patients with coronavirus disease 2019: A retrospective cross-sectional study. J Med Virol. 2020;2020;1-9. PMid:32458459

21. Tatum D, Taghavi S, Houghton A, Stover J, Toraih E, Duchesne J. Neutrophil-to-Lymphocyte Ratio and Outcomes in Louisiana COVID-19 Patients. Shock. 2020;54(5):652-8. doi: 10.1097/ SHK.0000000000001585.

PMID: 32554992. 